Natis (1)

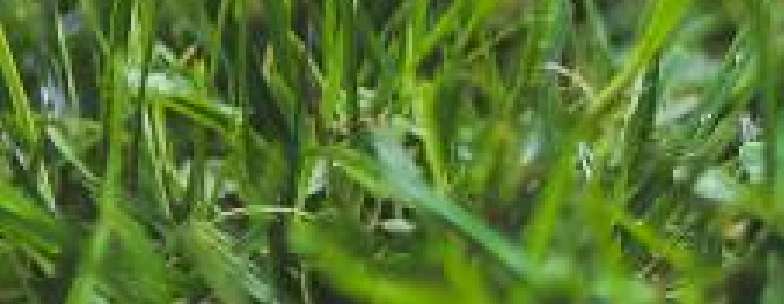

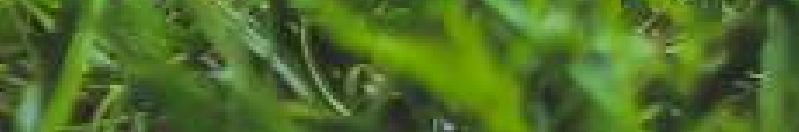

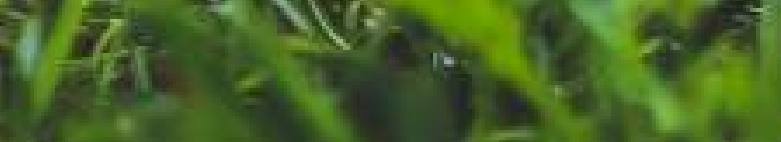

(1)

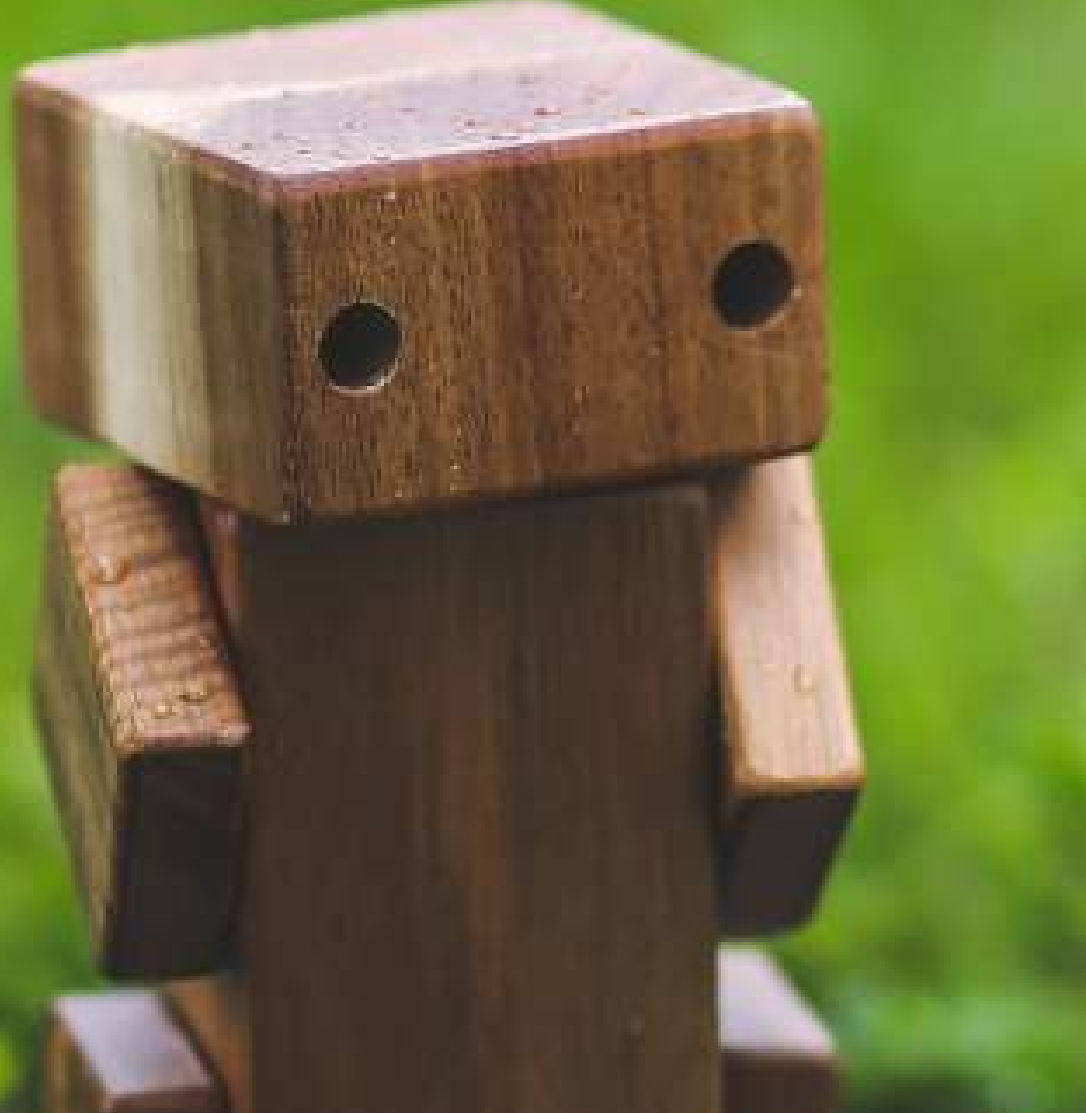
y.

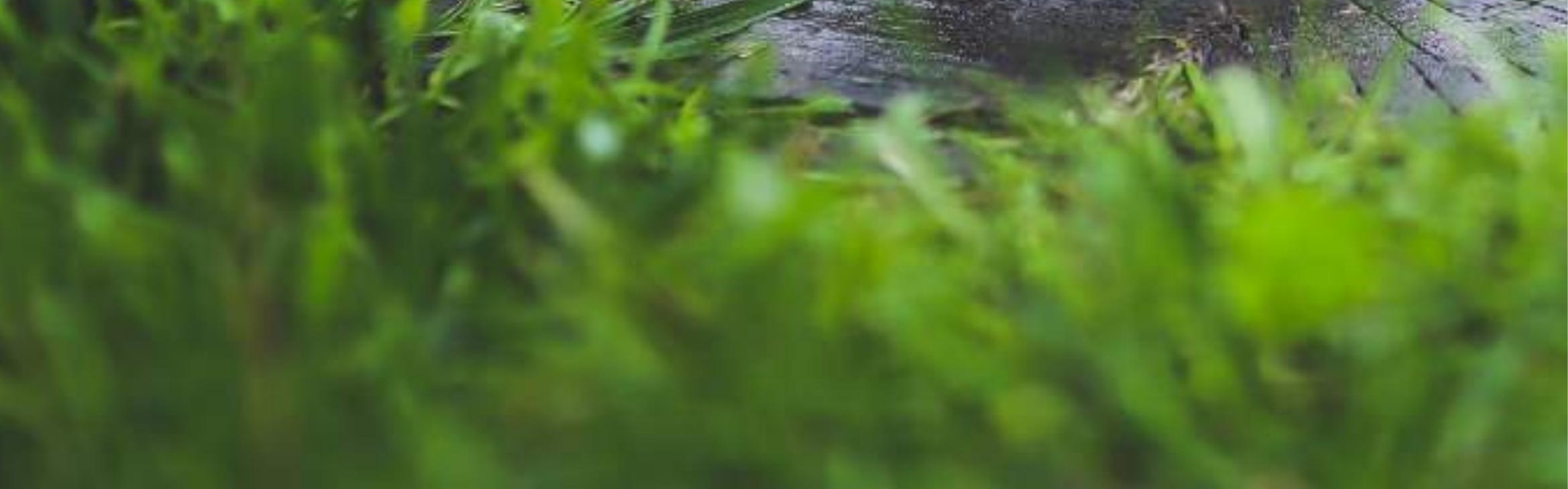




\section{Surco, te quiero verde}


S dos alguna vez soñamos, uno en el que las áreas verdes se han multiplicado. La tarea no ha sido fácil; han sido años de trabajo constante y de renovación total. Nos fijamos el objetivo de recuperar las áreas verdes y hoy podemos decir «tarea cumplida».

Surco cuenta con más de dos millones de metros cuadrados de áreas verdes, 365 parques distribuidos en los nueve sectores del distrito -de los cuales 132 han sido calificados como saludables por la Dirección General de Salud Ambiental e Inocuidad Alimentaria (Digesa) del Ministerio de Salud (Minsa)-, y más de 100 mil árboles que adornan avenidas, pasajes, óvalos, parques y urbanizaciones. En la misma direc- ción, se ha logrado embellecer todo el distrito gracias a la producción de 309000 plantas en los tres viveros surcanos, entre ellas, árboles, flores, plantas ornamentales y medicinales.

Nuestros vecinos han sido los mejores aliados para transformar el comportamiento de los residentes surcanos con respecto al cuidado del medio ambiente. Hemos logrado impulsar el Programa de Segregación en Origen «En Surco la Basura Sirve», que consiste en motivar la participación de los vecinos en la selección de residuos reciclables desde sus casas para que sean procesados en la planta de reciclaje del distrito y se puedan fabricar carpetas escolares, sillas, casetas de seguridad, bancas, entre otros.
El programa ha sido un éxito y hoy cuenta con la intervención de 33000 familias, treinta condominios, veinte establecimientos comerciales, tres universidades y diez instituciones educativas; todos están capacitados por los promotores ambientales, personal especializado en el desarrollo de estrategias para cuidar la ecología. Contamos, además, con treinta y tres contenedores soterrados instalados en diversos sectores del distrito, que logran recolectar entre catorce $\mathrm{y}$ dieciséis toneladas diarias de material reciclable.

La fábrica de bolsas de la Municipalidad de Santiago de Surco es otro programa exitoso, pues podemos decir con orgullo que producimos más de 700000 bolsas anaranjadas al mes

Figura 1. Parque Árabe Palestino - Santiago de Surco

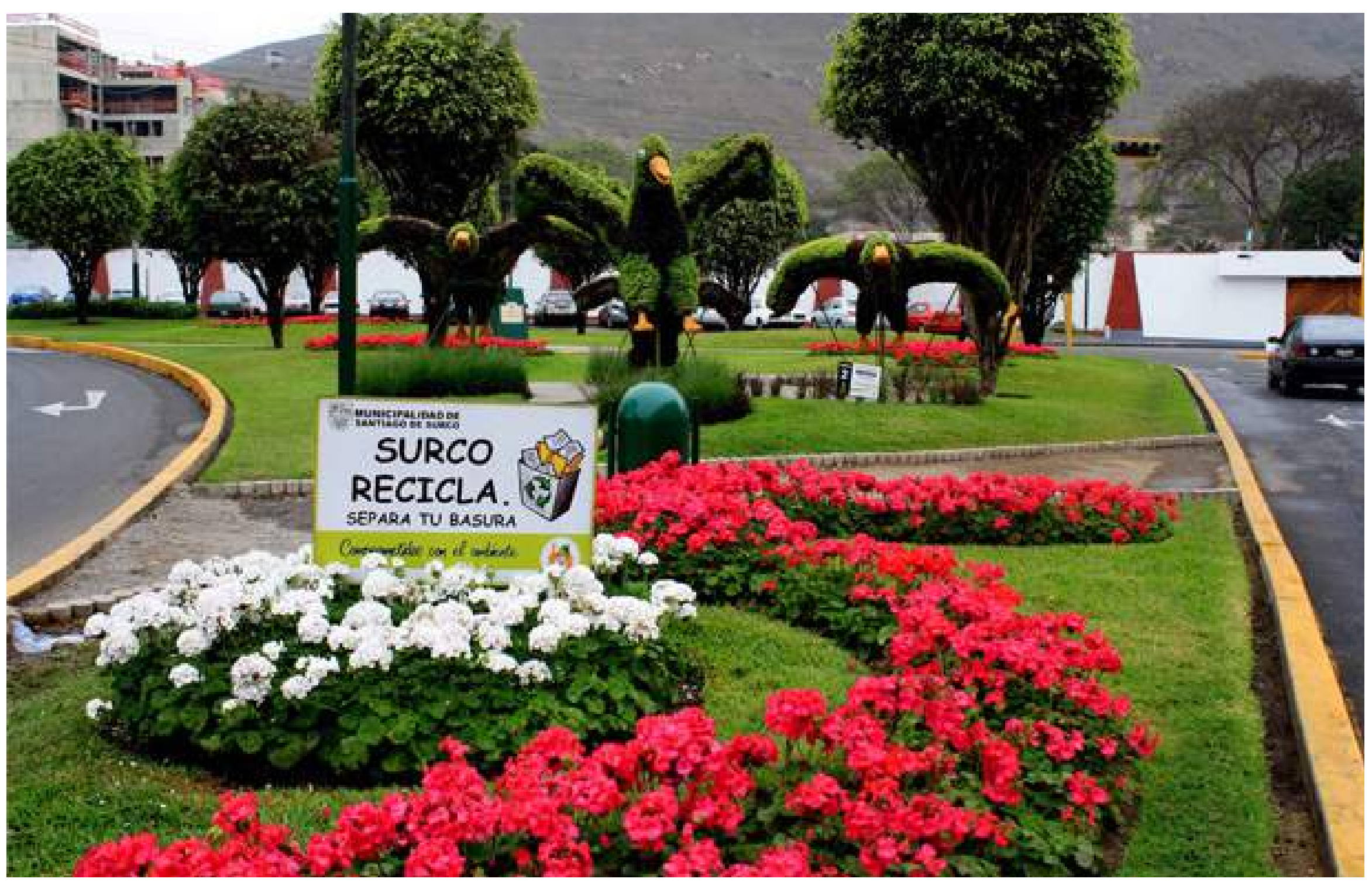

Fuente: Municipalidad de Santiago de Surco (2016) 
siguiendo la metodología de reciclaje «bolsa que sigue siendo bolsa». En tanto, uno de nuestros proyectos más ambiciosos es concretar la obra más significativa en materia de reciclaje: el Parque Ecológico de Surco o Complejo Ecológico, que se construirá sobre un terreno de 40000 $\mathrm{m}^{2}$ y donde se invertirán 10000000 de soles aproximadamente. El complejo contará con lagunas de almacenamiento, que permitirían tratar las aguas del canal del río Surco, y con una planta de tratamiento de aguas residuales, que se sumaría a las que ya existen en la zona de Intihuatana y el Parque de la Amistad (1 240000 litros de agua tratada),

Figura 2. Esculturas vegetales (oso panda) en la avenida Ayacucho

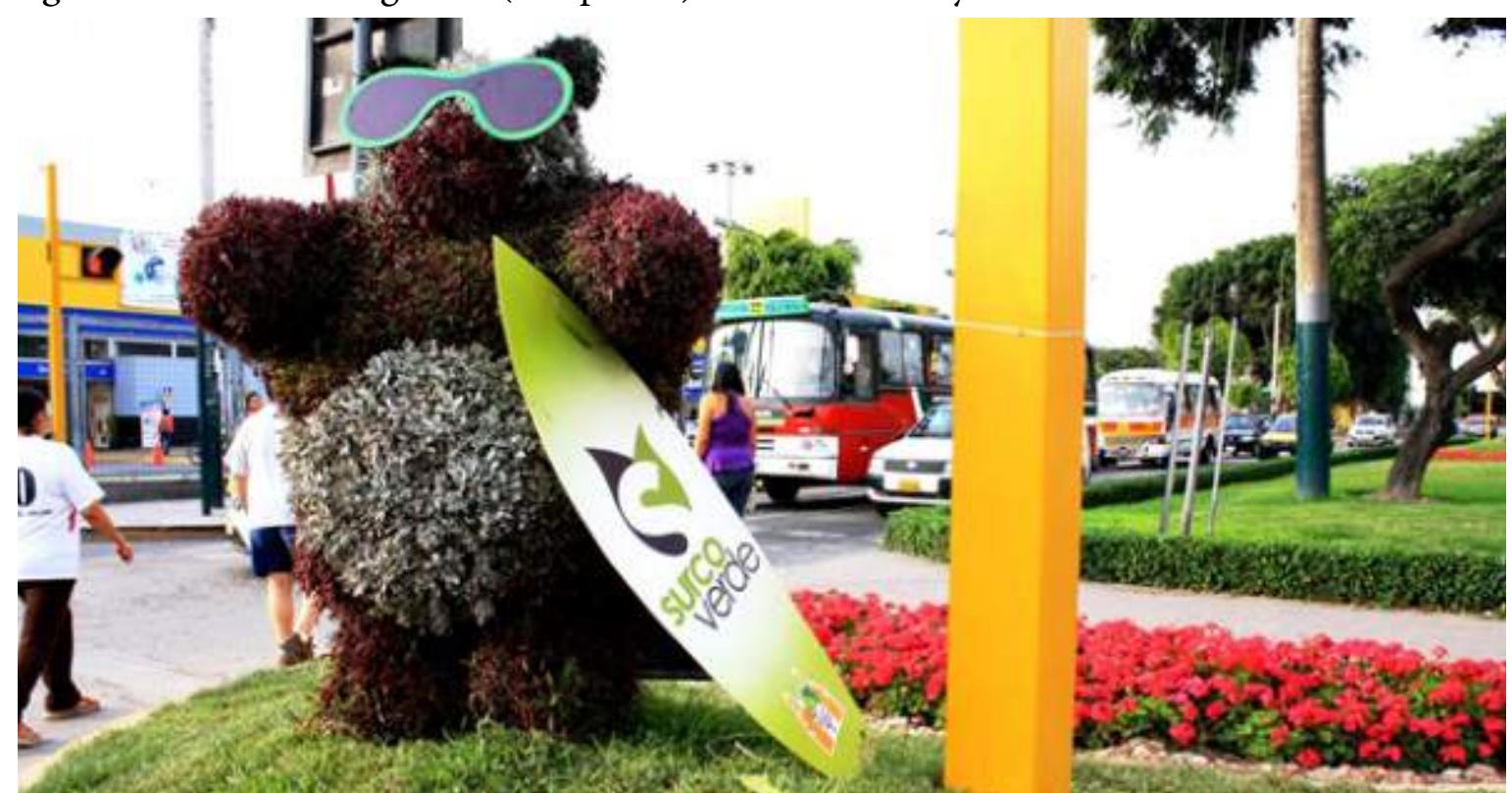

Fuente: Municipalidad de Santiago de Surco (2016)

Figura 3. Esculturas vegetales (patos) en el óvalo de la UPC

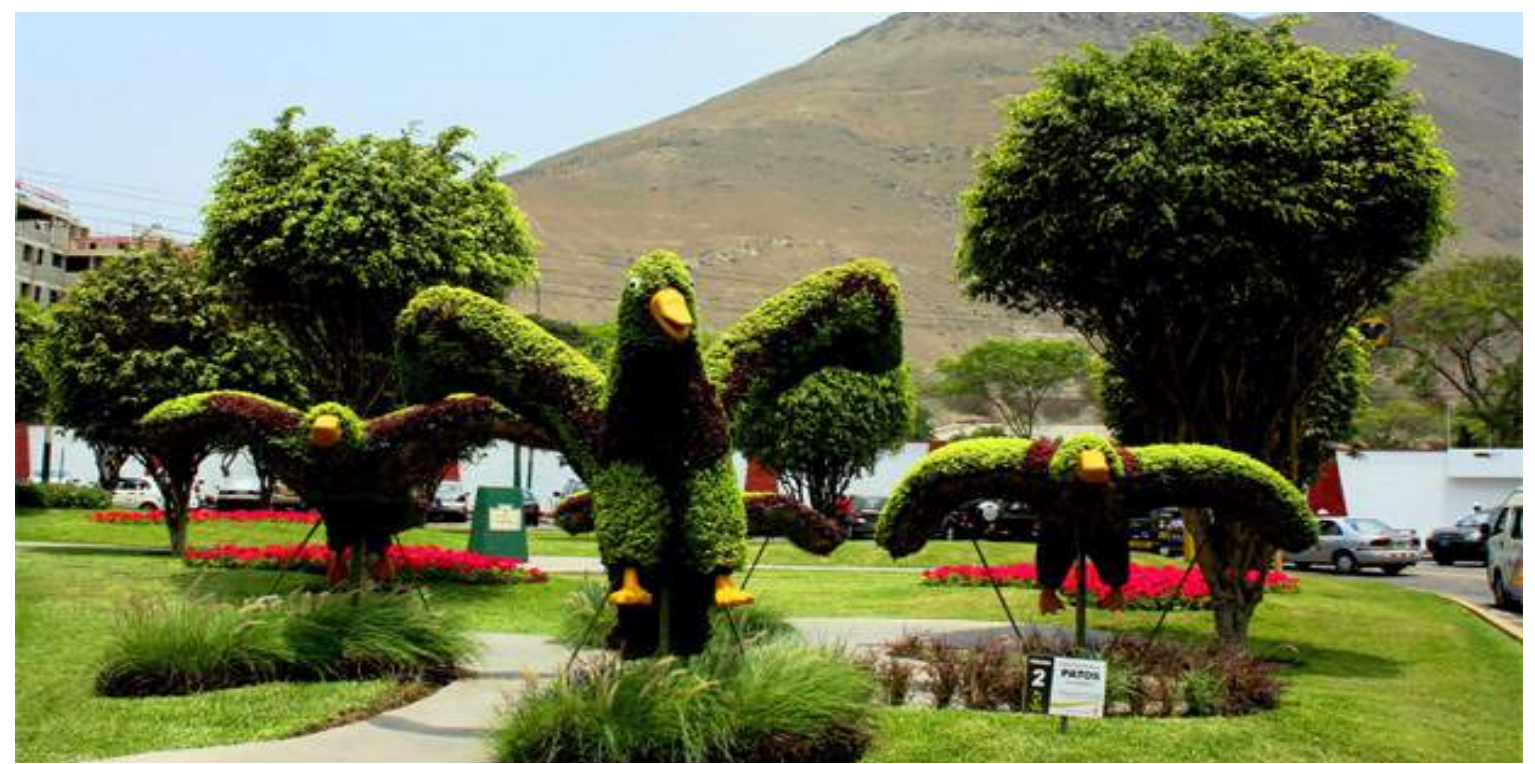

Fuente: Municipalidad de Santiago de Surco (2016) aguas con las que se riega el $50 \%$ de las áreas verdes de todo el distrito.

Seguimos enfocados en ser un distrito verde y una muestra de ello es la transformación del Complejo Loma Amarilla, construido sobre siete hectáreas en el centro de Surco. Se trata de una obra emblemática que protege el planeta donde vivimos. Loma Amarilla es un lugar donde los vecinos pueden practicar deporte, pasear en familia, y disfrutar del aire libre en un bosque con árboles medicinales y flora que propician la vida sana. Este complejo es hoy el pulmón ecológico de Surco.
«Surco, te quiero verde» más que un eslogan es un objetivo que cumplimos a favor de los vecinos y del cuidado del ambiente, fin importante a nivel mundial. 
Figura 4. Vivero municipal

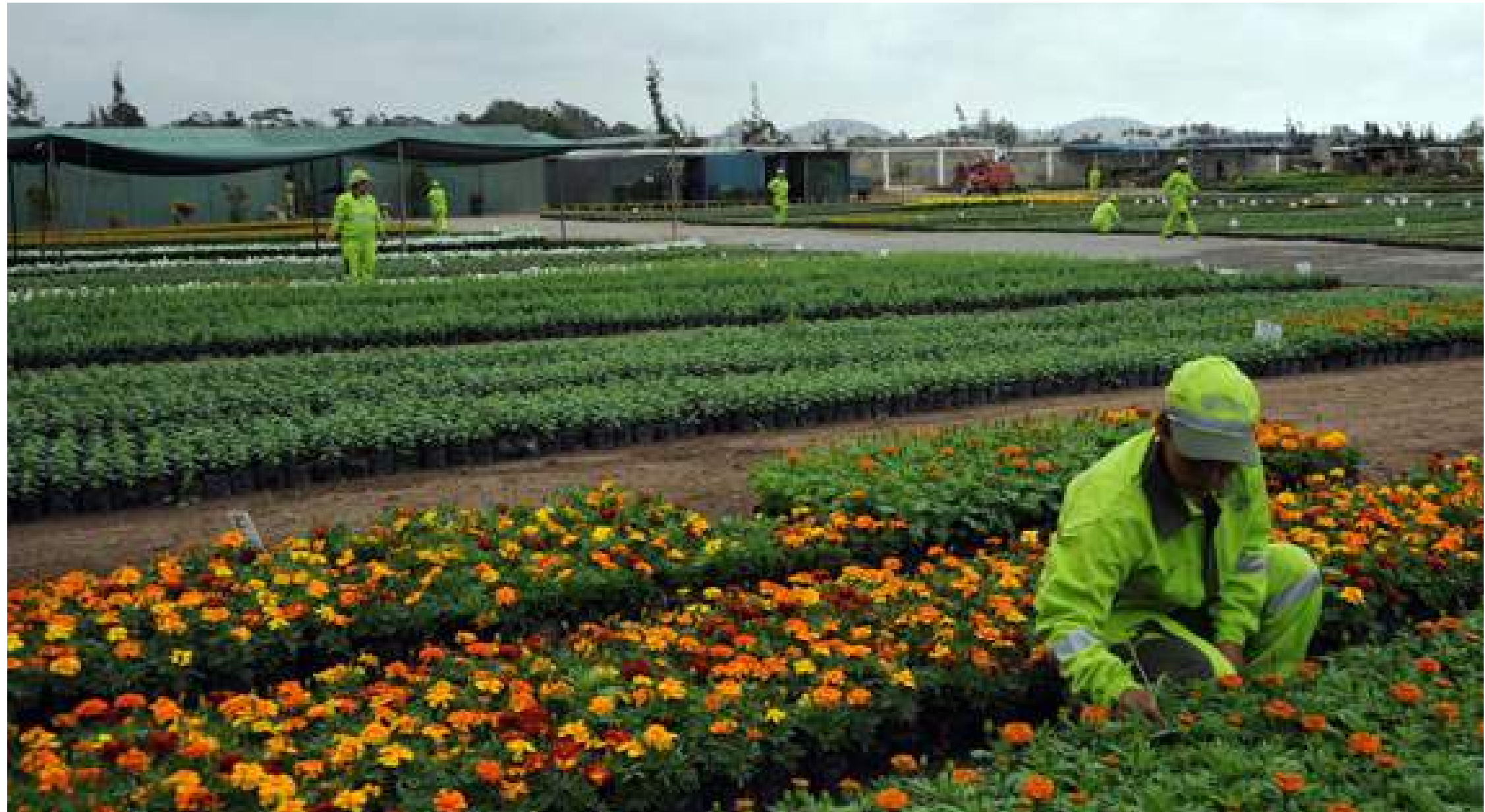

Fuente: Web de la Municipalidad de Santiago de Surco (2016)

Figura 5. Loma Amarilla

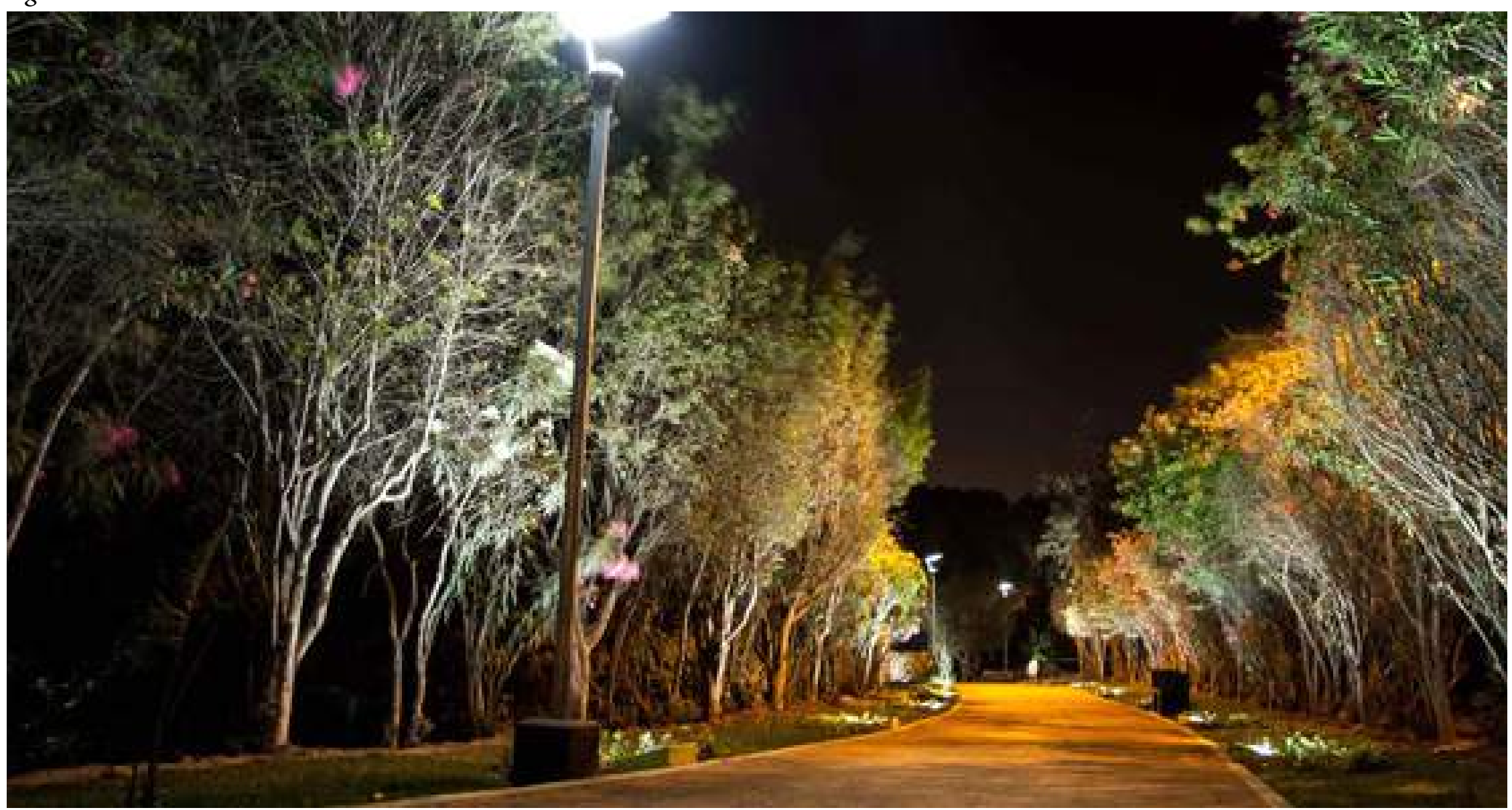

Fuente: Web de la Municipalidad de Santiago de Surco (2016) 
Figura 6. Mural en el Complejo Ecológico de Surco

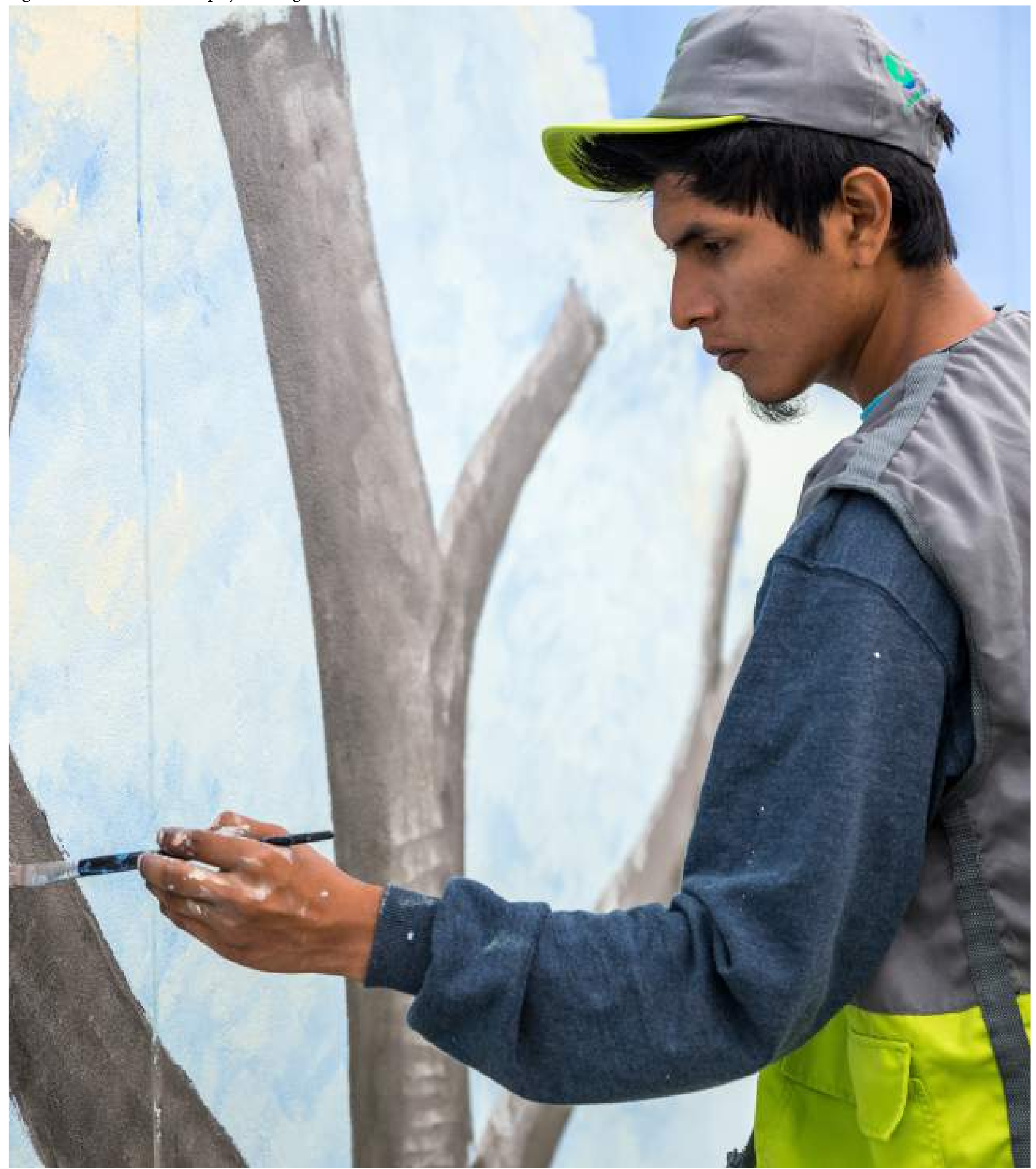

Fuente: Asociación Aire Cultura Urbana (2016) 